\title{
Instigation of Sulfas Ferosus Tablet Consumption Using Video and Sulfas Ferosus Tablet Diary; Case Report in Banjarmasin Indah Public Health Centre, Banjarmasin, South Kalimantan, Indonesia
}

\author{
Meitria Syahadatina Noor* \\ Faculty of Medicine, \\ Lambung Mangkurat University, \\ Banjarmasin, South Kalimantan, Indonesia \\ Dessy Amalina \\ Faculty of Medicine's student, \\ Lambung Mangkurat University, \\ Banjarmasin, South Kalimantan, Indonesia
}

\author{
I Gede Bagus Raiputra Pratama \\ Faculty of Medicine's student, \\ Lambung Mangkurat University, \\ Banjarmasin, South Kalimantan, Indonesia \\ Vivi Arfiani Ahmad \\ Faculty of Medicine's student, \\ Lambung Mangkurat University, \\ Banjarmasin, South Kalimantan, Indonesia
}

\begin{abstract}
Anaemia is a condition with hemoglobin less than $11 \mathrm{~g} / \mathrm{dl}$. It is a potential danger to mother and child. Based on Banjarmasin Indah Public Health Centre January-October 2018, 243 pregnant women checked their hemoglobin, and there were 99 pregnant women (40.7\%) who suffered anaemia. Of 99 pregnant women with anaemia, only 18 pregnant women $(18.2 \%)$ regularly consumed sulfas ferosus tablets. The method used experimental quasy research by instigation as the intervention. The first survey was done from 20 anaemia pregnant women to know the reasons for iron consumption unregularly. The results were they had good knowledge $80 \%$ and not good knowledge 20\%; always remembered to consume sulfas ferosus tablets 100\%; felt lazy to consume sulfas ferosus tablets $80 \%$ and felt not lazy 20\%; felt side effects such as nausea 50\% and didn't feel side effects 50\%. Instigation about consuming sulfas ferosus tablets and decreasing side effects was done using video and sulfas ferosus tablet diary. Its goal was to increase the achievement of sulfas ferosus tablet consumption. Instigation was done on pregnant women who visited Banjarmasin Indah Public Health Centre (14 women). Knowledge and motivation of them were evaluated before and after the instigation. The evaluation from all of the pregnant women who attended had shown increasing knowledge and motivation before and after instigation. Score of knowledge was 53,57 became 77,14; $p$ value $=0.000$ with paired $t$ test $95 \%$. Score of motivation was 41.43 became $46.07 ; p$ value $=0.000$ with Wilcoxon test $95 \%$. The conclusion was that using video and sulfas ferosus tablet diary could increase the knowledge and motivation of pregnant women to consume sulfas ferosus tablets and decrease the side effect.
\end{abstract}

Keywords: Anaemia pregnant women, side effect of sulfas ferosus tablets, instigation

Received: 04 October 2018; Accepted: 29 October 2018; Published: 14 November 2018

\section{INTRODUCTION}

Anaemia in pregnant women is a condition that has haemoglobin level less than $11 \mathrm{gr} / \mathrm{dl}$ [1]. Prevalence of anaemia in developed countries was about $9 \%$, and in developing countries was about $43 \%$. Prevalence of anaemia in pregnant women was about $43 \%$ [2]. Proportion of pregnant women who suffered anaemia in Indonesia was about $48.9 \%$, and most of them were in $15-24$ years old [3]. Anaemia in pregnant women mostly was caused by lack of iron consumption and absorbtion [4]. Preg-

\footnotetext{
${ }^{*}$ Correspondence concerning this article should be addressed to Meitria Syahadatina Noor, Faculty of Medicine, Lambung Mangkurat University, Banjarmasin, South Kalimantan, Indonesia. E-mail: drmeitria@yahoo.com

(c) 2018 The Author(s). Published by KKG Publications. This is an Open Access article distributed under a Creative Commons AttributionNonCommercial-NoDerivatives 4.0 International License.
} 
nant women who got sulfas $\geq 90$ sulfas ferosus tablets (complete program) to prevent and cure anaemia in South Kalimantan year of 2017 were only $60.89 \%$ [5, 6].

Based on registration data of pregnant women in Banjarmasin Indah Public Health Centre, there were 99 pregnant women from 243 pregnant women $(40.7 \%)$ who suffered anaemia. From 99 pregnant women with anaemia, there were only 18 pregnant women who got sulfas ferosus tablet $(18.1 \%)$. The achievement of sulfas ferosus distribution for pregnant women in Banjarmasin Indah Public Health in January-October 2018 was only 18.1\% [7]. It might be caused by unregular consumption of sulfas ferosus for some reasons, and then not getting the program.

Anaemia in pregnant can cause morbidity and mortality for mother and her baby. The effects are low birth bodyweight, infection, abortion, and premature delivery $[8,9]$. Other effects may include low productivity and cognitive disturbances [10].

Some risk factors that could cause anaemia in pregnant women were chronic energy loss, education and knowledge level, and regularity of sulfas ferosus consumption. Factors that could cause unregular sulfas ferosus tablets consumption were knowledge of sulfas ferosus tablets was low, side effects that gave uncomfort to pregnant women, lazy to consume, or forget to consume. Side effects of sulfas ferosus tablets consist of nausea, vomiting, dark feces, and stomacache because of wrong way of consumption [11], [12]; [13].

Compliance of sulfas ferosus tablet consumption depend on some factors. Based on Lawrence Green theory, the factors were predisposing factors (knowledge, attitude, belief, value, and intention); enabling factors (transportation, distance to public health service, health service, advise and infrastructure); and reinforcing factors (support from family, public figure, health worker, etc.). Those factors were found in [14] research about compliance of teraphy.

Problem in uncompliance of sulfasferosus tablet consumption must be solved. One of ways to solve the behavior problem is health promotion with instigation. Method of health promotion that is suitable for all of educational level is discourse and discussion. The best media of health promotion to make high retention of memory is audiovisual ( $85 \%$ of retention). Based on that, this research used discourse and discussion and audiovisual media as the intervention to solve the problem.

In this case, anaemia in pregnant women in Banjarmasin Indah public health centre were many, but achievement of sulfas ferosus tablet distribution was low. Some of them consumed sulfas ferosus tablet unregularly. Sur- vey to know the cause of unregular sulfas ferosus tablets consumption in Banjarmasin Indah Public Health Centre have not been done. Variation of health promotion related to anaemia in pregnant women and sulfas ferosus tablet to solve the probem was not many, so this research was need to explore to know the reason and directly do the intervention to make the change to uncompliance of sulfas ferosus tablet consumption.

\section{A. Objective of the Study}

This research's goal was analyzing the cause of unregular sulfas ferosus tablets consumption and analyzing the change of knowledge and motivation of pregnant women after instigation.

\section{LITERATURE REVIEW}

Anaemia in pregnant woman is a condition that haemoglobin level lower than $11 \mathrm{gr} / \mathrm{dl}$. Most of the cause is iron deficiency. Classification of anaemia based on the severity concist of mild anaemia if haemoglobin level is 8-11 gr/dl, ang severe anaemia if the haemoglobin level is less than $11 \mathrm{gr} / \mathrm{dl}$ [15].

Etiologies of anaemia in pregnant women are lack of iron, vitamin B12 and folic acid, malabsorbtion, and hematology changes. Plasma volume in pregnant increase $45-65 \%$, so haemoglobin level become lower [16]. Risks factors that can cause anaemia in pregnant women are: [17]

\section{A. Basic Factors}

- Good social an economic condition will increase the ability to get good quality of nutrition to decrease anaemia

- Good education and knowledge will make good awareness to prevent anaemia

\section{B. Undirect Factors}

- Ante natal care: observation of pregnant condition before delivery, consist of examination of healthy condition for mother and foetus include nutrition status

- Age of mother: if the age is too young $(<20$ years old) will need more nutrition for her growth and development and also the foetus in her content. But if the age is too old, the function of organ have decreased and some disturbances happens.

\section{Direct Factors}

- Sulfas ferosus tablets consumption to prevent and treat iron deficiency in pregnant women.

- Time distance between 2 pregnant must be more than 2 years to decrease anaemia in pregnant. 
- Parity: the number of pregnant that a woman ever had. More parity makes a risk to anaemia.

- Nutrition status of woman: low nutrition status in woman makes low oxygen and nutrition circulation for the baby and the mother

- Chronic infection diseases can cause anaemia, such as tuberculosis and wormy disease.

Anaemia in pregnant can cause morbidity and mortality for mother and her baby. The effects are low birth bodyweight, infection, abortion, and premature delivery $[8,9]$. Other effects may include low productivity and cognitive disturbances [10]. Pregnant women who suffer anaemia can induce bleeding in delivery and can cause death. Deficiency iron anaemia in pregnant women can decrease iron saving in foetus. It can cause anaemia also to the baby [4].

Eradication programs to decrease anaemia in pregnant women are: (Prawirohardjo as cited in [17]).

a. High iron nutrition sources such as fish, meat, and green vegetables. This way must be followed by high vitamin $\mathrm{C}$ consumption to increase iron absorbtion.

b. Fortification of iron in many kinds of food

c. Supplementation of iron (sulfas ferosus tablets)

Supplementation of iron for pregnant women consists of iron and folic acid. Dose of folic acid is $500 \mathrm{mg}$, and iron is $120 \mathrm{mg}$. supplementation of iron $30 \mathrm{~g} /$ day will increase $0,3 \mathrm{~g} / \mathrm{dl} /$ weak or in 10 days. Food that contains iron also important, such as beef, chicken, wheat bread, peanutsgreen vegetables, spinach, egg, etc [18].

Program of iron supplementation (sulfas ferosus tablet) in Indonesia consists of supplementation for fertile women and pregnant women. Supplementation for fertile women is only once in a week and once in a day in in menstrustion cycle. Supplementation for pregnant women gives everyday at least 90 tablets in pregnant time. Composition of supplementation in this program contain 60 $\mathrm{mg}$ iron (ferro sulfat, ferro fumarate, or ferro gluconate) and 0,400 mg folic acid. The specification is dark red, round, and sugar coated tablet (Indonesia Health Ministry, 2014).

This program can be success if followed by health promotion. Health promotion needs suitable method and media. Types of health promotion's method are: [19]

1. Individual method: it is suitable for new behavior or develop someone who interesting to positive behavior or innovation. It is for individual problem, because everybody has his/her own different problem.

2. Group method

a. Big group: the participants must be more than 15 people. The method uses discourse, that is suitable for all of eduvation level. b. Small group: the participants less than 15 people.

- Discussion: expressing opinions to solve the problems together

- Brain storming: also the same with discussion but it was started by a case as an induction of discussion. Participants only be allowed to give opinions after all of the participants have given the opinions

- Snow balling: the group is divided into more small group first. After that, part of group discuss with the other group, etc an the end all of them discuss in all group again.

- Buzz group: group is divided into some small groups that discuss same or different problem. After that, all of the small group discuss together to make the conclusion.

- Role play

- Simulation game: combination between role play and discussion.

3. Mass method: this method is tranfering information to community. The information is general to ask the awareness of community. This method consists of public speaking, mass media, simulation, writing in magazine or newspaper and bill board.

To transferring the information, health promotion needs media. Types of promotion media are: [19]

1. Printing media: consists of visual information. The examples are leaflet, booklet, flyer, flip chart, poster, photograph, magazine, and newspaper.

2. Electronic media: this media is moving and dynamic, can be seen and heard. This media is more interesting and be understood easily. The examples are television show, video, radio, $\mathrm{CD}, \mathrm{VCD}$, and internet.

3. Outdoor media: it is used out of the building. It can be printing media that is put out of the building.

4. Other media: the promotion can be put on bus or other transportation types, event, roadshow, give the sample of product, etc.

\section{RESEARCH MODEL}

This research consisted of 2 steps. Step 1 was survey to know the reasons of unregular sulfas ferosus consumption. Step 2 was intervention by giving instigation of sulfas ferosus tablet consumption using video and sulfas ferosus tablet diary, and then knowledge and motivation to consume sulfas ferosus tablets were investigated. Problem tree and the concept of research was in Fig. 1.

\section{A. Step 1}

This step used descriptive observational. Survey was done in 20 anaemia pregnant women who registered in Banjarmasin Indah Public Health Centre. Survey was about the reasons of unregular sulfas ferosus consump- 
tion based on the concept diagram above. The data was tabulated and calculated the percentage of each reasons.

\section{B. Step 2}

This step used quasy experimental research to analyze knowledge and motivation of anaemia and sulfas ferosus tablet before and after instigation. The subjects were all of the pregnant women who visited Banjarmasin Indah Public Health Centre in 1 day of ante natal care service. The number were 14 pregnant women. The concept of this research showed in Fig. 1.

Fig. 1 showed that the problem was unregular of sulfas ferosus tablet consumption. It could cause anaemia in pregnant women. Risk factors of unregular consumption were internal and external factors. Internal factors were knowledge, forgot to consume, and lazy to consume. External factors were the tablet itself. It could cause uncomfort taste and side effects.

The method of instigation was discourse with audiovisual media, discussion, and video. This method was one of ways in health promotion to explain and transfer knowledge, followed by discussion and distribution of sulfas ferosus tablet diary to increase regularity of sulfas ferosus tablet consumption. The diary was showed in Fig. 2 and 3.

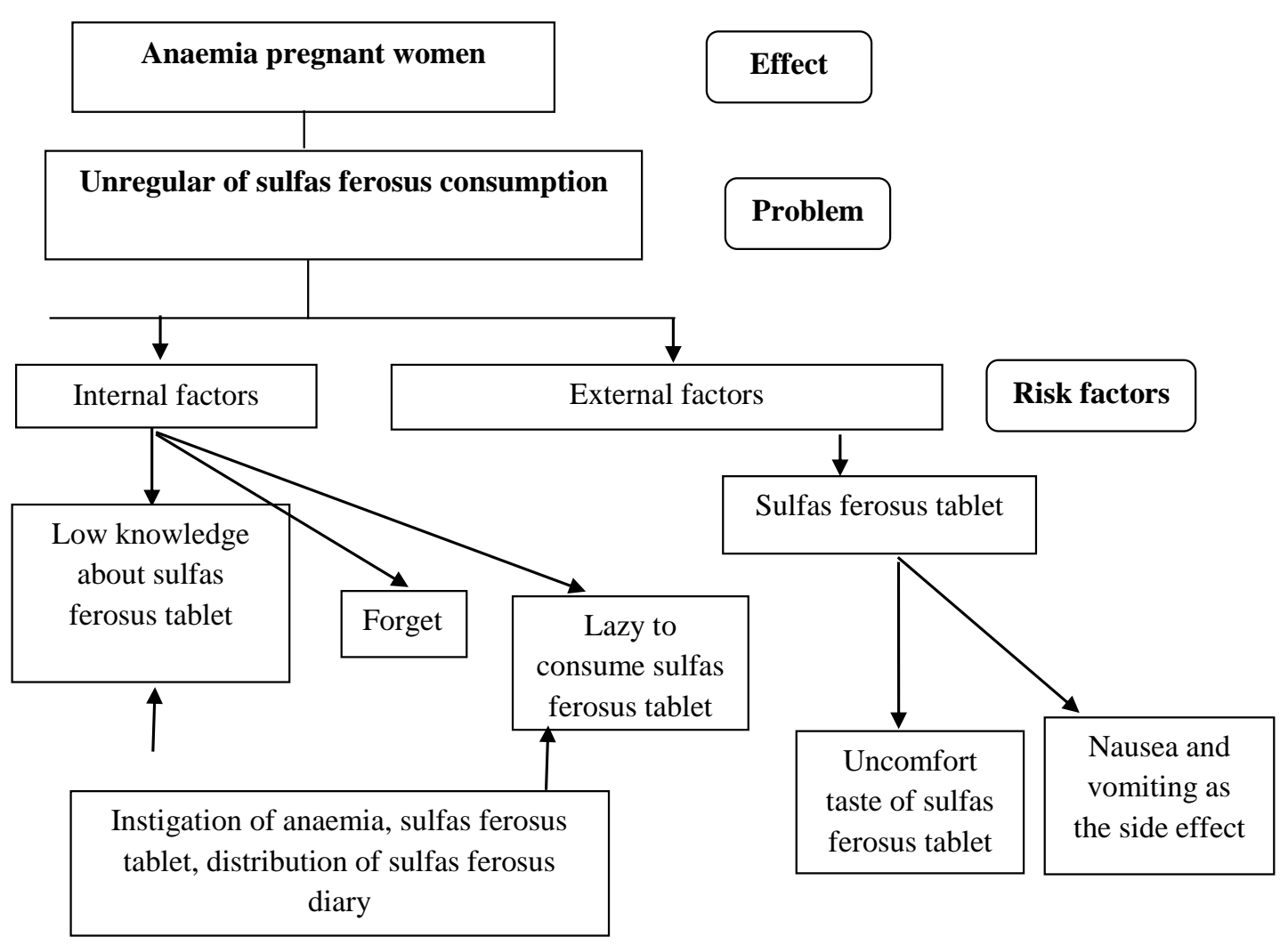

Fig. 1. Concept diagram of research

Risk factors were observed by survey in 20 anaemia pregnant women. Internal risk factors were solved by instigation to all of pregnant women who visit ante natal care in Banjarmasin Indah Public Health Centre.

The independent variable was instigation. The dependent variables were knowledge and motivation of sulfas ferosus tablet consumption before and after instigation. They were investigated by quessionnaires. Data scale of each variables was numeric. The data must be tested by normality and homogeneity test. If data were in normal distribution and homogen, they were analyzed by paired- $t$ test with $95 \%$ significance level.

Media that was used for instigation were audiovisual and sulfas ferosus tablet diary. The diary consisted of information and table for making a note if have consumed. It will prevent the forgetness. 


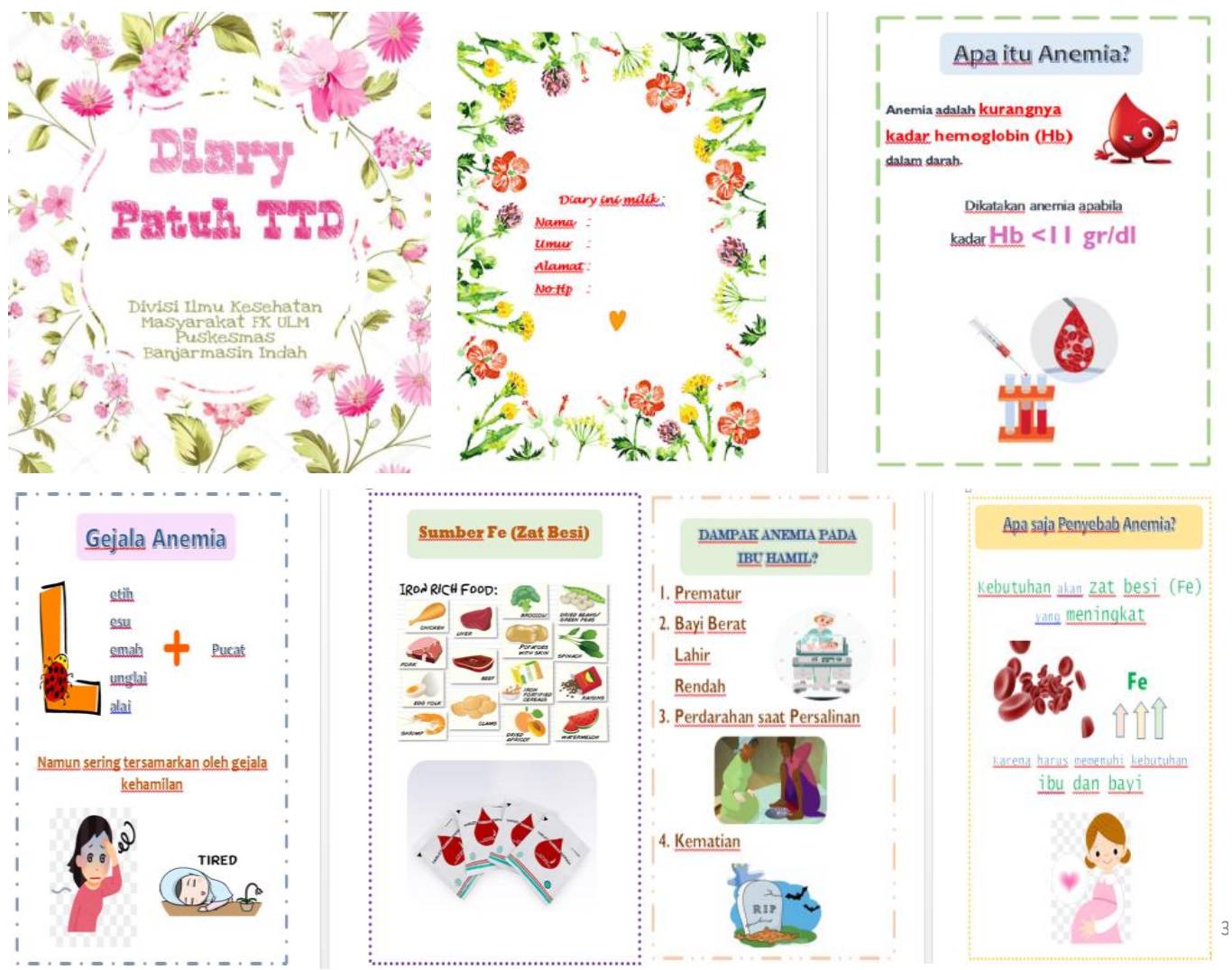

Fig. 2. Information about anaemia and sulfas ferosus tablet in diary
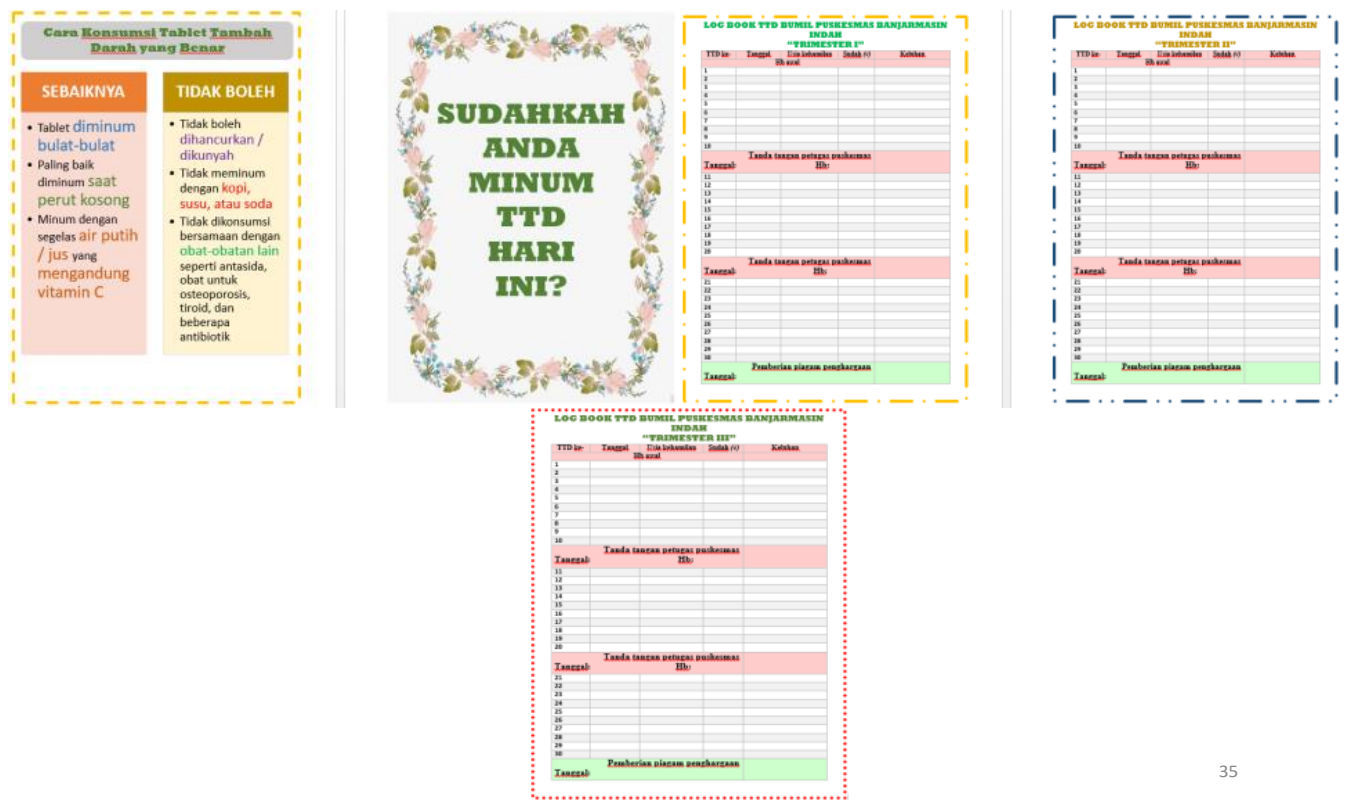

Fig. 3. Reminder table in Sulfas ferosus tablet diary

\section{DATA ANALYSIS}

A. Step 1

The result of suvey about the reasons of unregular sulfas ferosus tablet consumption were in Table 1. 
TABLE 1

RESULT OF REASONS OF UNREGULAR SULFAS FEROSUS TABLET CONSUMPTION

\begin{tabular}{|c|c|c|c|}
\hline Reasons in Survey & Positive & Negative & Total \\
\hline $\begin{array}{l}\text { Knowledge about sulfas ferosus } \\
\text { tablet }\end{array}$ & $\begin{array}{l}80 \% \text { ( } 16 \text { women) of good } \\
\text { knowledge }\end{array}$ & $\begin{array}{l}20 \% \text { ( } 4 \text { women) of less } \\
\text { knowledge }\end{array}$ & 20 women $(100 \%)$ \\
\hline $\begin{array}{l}\text { Forget to consume sulfas ferosus } \\
\text { tablaet }\end{array}$ & $\begin{array}{l}100 \% \text { ( } 20 \text { women) remem- } \\
\text { bered }\end{array}$ & Forgot $0 \%$ & 20 women $(100 \%)$ \\
\hline $\begin{array}{l}\text { Side effect of sulfas ferosus tablet } \\
\text { (nausea and vomiting) }\end{array}$ & $\begin{array}{l}50 \% \text { (10 women }) \text { who } \\
\text { didn't suffer side effect }\end{array}$ & $\begin{array}{l}50 \% \text { ( } 10 \text { women }) \text { who suf- } \\
\text { fered side effect }\end{array}$ & 20 women $(100 \%)$ \\
\hline $\begin{array}{l}\text { Lazy to consume sulfas ferosus } \\
\text { tablet }\end{array}$ & $\begin{array}{l}20 \% \text { ( } 4 \text { women) who were } \\
\text { not lazy }\end{array}$ & $\begin{array}{l}80 \% \text { (16 women) who } \\
\text { were lazy }\end{array}$ & 20 women $(100 \%)$ \\
\hline
\end{tabular}

B. $\quad$ Step 2

Data in step 2 consisted of knowledge and motivation before and after instigation in Table 2 .

TABLE 2

KNOWLEDGE AND MOTIVATION BEFORE AND AFTER INSTIGATION

\begin{tabular}{lllll} 
No. & \multicolumn{2}{c}{ Before Instigation } & \multicolumn{2}{c}{ After Instigation } \\
\cline { 2 - 5 } & Knowledge & Motivation & Knowledge & Motivation \\
\hline 1. & 80 & 40 & 100 & 46 \\
2. & 60 & 42 & 70 & 43 \\
3. & 70 & 43 & 90 & 47 \\
4. & 60 & 38 & 90 & 48 \\
5. & 40 & 43 & 70 & 48 \\
6. & 50 & 44 & 70 & 48 \\
7. & 50 & 43 & 60 & 43 \\
8. & 50 & 43 & 60 & 43 \\
9. & 20 & 35 & 90 & 49 \\
10. & 70 & 42 & 80 & 42 \\
11. & 60 & 28 & 80 & 49 \\
12. & 60 & 44 & 90 & 44 \\
13. & 30 & 49 & 50 & 49 \\
14. & 50 & 46 & 80 & 46 \\
Mean & 53.57 & 41.43 & 77.14 & 46.07 \\
\hline
\end{tabular}

Data of knowledge increased from 53.57 in pretest became 77.14 in post test. Data of motivation increased also from 41.63 in pretest became 46.07 in post test.

Data of knowledge were in normal distribution ( $p$ value of Saphiro Wilk test >0.05), and then they were analyzed by paired- $t$ test with $p$ value 0.000 . Data of motivation were not in normal distribution ( $p$ value of Saphiro Wilk test $<0.05$ ), and then they were analyzed by Wilcoxon test with $p$ value 0.000 .

\section{DISCUSSION}

Table 1 showed that the most reasons of unregular sulfas ferosus consumption were suffering side effects such as nausea and vomiting (50\%) and lazy to consume sulfas ferosus tablets $(80 \%)$. These reasons were related each other. Someone was lazy to consume because felt uncomfort in consuming the tablets. That condition made someone consume sulfas ferosus tablet unregularly.

This result almost the same with [20]. That tesearch showed that 58 women of 90 women (64.4\%) felt side effect of sulfas ferosus tablet. Group that felt side effect 
and didn't obey to consume sulfas ferosus was $72.4 \%$. The analysis of this [20] research was significant association between side effect and compliance of sulfas ferosus consumption with $p$ value 0.007 . Some side effects that could happen in consuming sulfas ferosus tablet were nausea, vomiting, stomachace, diarrhea, dizziness, and constipation [21].

Table 2 showed that there was increasing of score knowledge and motivation after instigation. Increasing of knowledge showed that pregnant women in this research had more information about sulfas ferosus tablet. Increasing of motivation showed that pregnant women in this research wanted to consume the tablet regularly.

This positive effect was caused by intigation method. The methode used audiovisual (combination between pictures in explanation and video as visual show and discourse and discussion as audio show). This methode made the audience got information easily.

Beside that, another media that was used in the instigation was sulfas ferosus diary. It consisted of information about anaemia and sulfas ferosus tablet. This diary also could increase motivation because it was included the table to be fulfilled if had consumed the tablet. This diary decrease forgetness to consume and the information increase the knowledge abut sulfas ferosus tablet and its goodness.

Audiovisual media could increase perception, understanding ability, transfer of knowledge, reinforcement of content, and increase retention of memory. This media was not boring, easy to be understood, and the information was more clear [22].

Some methods could be choosen for the instigation. This instigation used group discourse because it was suitable for all of education level. The information was tranfered oral. To prevent one way information, discourse method should be followed by discussion. Discussion could solve problem and express the opinions. But discussion should be done in small group, not effective among many people [19].

To transfer information, instigation need media. Media is something that can be seen, heard, and written. Reading and listening will give less memory retention after instigation than visual and role play or simulation. Role play and simulation will give the most memory retention [19]. The length of memory retention using some media was showed in Table 3.
TABLE 3

THE LENGTH OF MEMORY RETENTION [19]

\begin{tabular}{llll} 
No & Media & After 3 Hours & After 3 Days \\
\hline & & & \\
1 & Verbal & $70 \%$ & $10 \%$ \\
2 & Visual & $72 \%$ & $20 \%$ \\
3 & Verbal-visual & $85 \%$ & $65 \%$ \\
\hline
\end{tabular}

So, the strengness of this instigation's method and media could increase knowledge ang retain longer than the other method and media.

\section{CONSLUSION}

The conclusions of this research were:

1. The reasons of unregular sulfas ferosus consumption in anaemia pregnant women, Banjarmasin Indah Public Health Centre, were side effects of the tablet (nausea and vomiting) and feeling lazy to consume the tablet.

2. Instigation of sulfas ferosus tablet consumption using video and sulfas ferosus tablet diary could increase knowledge and motivation of pregnant women to consume sulfas ferosus tablet in Banjarmasin Indah Public Health Centre.

The limitation of this research was difficult to collect the subjects of research, so this research only used pregnant women who came to ante natal care service in public health centre. Future research directions can be use the same method and media for more subjects or also for different health problems.

\section{ACKNOWLEDGEMENTS}

We would like to show our gratitude to public health clinical students in Faculty of Medicine Lambung Mangkurat University as the field assistents, Banjarmasin Indah public Health centre as the location of activity and the source of data, and Department of Public Health Faculty of Medicine Lambung Mangkurat University as the organizer of public health clinical practice.

We also would like to thank you for Faculty of Medicine, Lambung Mangkurat University that had given a chance to present this research in 5th international conference on multidisciplinary innovation in business engineering science and technology (MI-BEST-2019) by Global Illuminator in Hongkong 5-6th April 2019. We also thank greatfull for Global Illuminator to facilitate publishing this article. 


\section{REFERENCES}

[1] WHO, Guideline Daily Iron and Folic Acid Supplementation in Pregnancy Women. World Health Organization Geneva, Geneva, Switzerland, 2012.

[2] E. McLean, M. Cogswell, I. Egli, D. Wojdyla, and de Benoist B., "Worlwide prevalence of anaemia, WHO vitamin and mineral nutrition information system 1993-2005," Public Health Nutr, vol. 12, pp. 444-445, 2009.

[3] Basic Health Research, Main Results of Basic Health Research 2018. Health Development and Research Agency in Indonesian Health Ministry Jakarta, Jakarta, Indonesia, 2018.

[4] I. Tanziha, M. R. M. Damanik, L. J. Utama, and R. Rosmiati, "Risk factors of anaemia in pregnant women in Indonesia," Journal of Nutrition and Food, vol. 11, no. 2, pp. 143-152, 2016.

[5] Indonesian Helath Ministry, Regulation of Indonesian Health Ministry Nomor 882014 about Standard of Iron Supplementation for Fertile Women and Pregnant Women. Indonesian Health Ministry Jakarta, Jakarta, Indonesia, 2014.

[6] Indonesian Health Ministry, Data and Information: Indonesian Health Profile 2017. Indonesian Health Minisrty Jakarta, Jakarta, Indonesia, 2018.

[7] Banjarmasin Indah Public Health Centre, Pregnant Women Daily Regstration Book of Banjarmasin Indah Public Health Centre 2018. Banjarmasin Indah Public Health Centre Banjarmasin, Banjarmasin, Indonesia, 2018.

[8] M. M. Achebe and A. Gafter-Gvili, "How i treat anemia in pregnancy: Iron, cobalamin, and folate," Blood, vol. 129, no. 8, pp. 940-949, 2017. doi: https://doi.org/10.1182/blood-2016-08-672246

[9] W. Astriana, "Prevalence of anaemia in pregnant women based on parity and age," Journal of Health Sciences, vol. 2, no. 2, pp. 123-130, 2017.

[10] S. Horton and J. Ross, "The economics of iron deficiency," Food Policy, vol. 28, pp. 51-75, 2003.

[11] S. Suhartati, H. Nita, and R. Laila, "Association of anaemia in pregnant women to low birth bodyweight in Tanta Public Health Centre Tabalong Regency 2016," Health Dinamics, vol. 8, no. 1, pp. 45-54, 2017.

[12] D. A. Yanti and S. A., "Risk factors to anaemia in primigravida in pringsewu public health centre lampung," Journal of Nursing, vol. 6, no. 2, p. 15, 2016.
[13] Government of South Australia, "A guide to taking iron tablets," Bloodsafe, vol. 1, pp. 1-2, 2017.

[14] T. Siswantoro, "Analysis of the influence of predisposing, enabling, and reinforcing factors on compliance of pulmonary TB treatment in bojonegoro," Journal of Health Policy Administration, vol. 10, no. 3, pp. 152-158, 2012.

[15] Indonesian Health Department, "Analysis of risk factors causing anaemia of pregnant women in Tawangsari Public Health Centre Sukoharjo Regency," Faculty of Health Sciences, Muhammadiyah University of Surakarta, Surakarta, Indonesia, Tech. Rep., 2013.

[16] Rukiyah, Midwifery Care I: CV. Jakarta, Indonesia: Trans Info Media Jakarta, 2010.

[17] Nurhidayati, "Analysis of risk factors causing anaemia of pregnant women in Tawangsari public health centre Sukoharjo Regency," Unpublished theis, Faculty of Health Sciences, Muhammadiyah University Surakarta, Surakarta, Indonesia, 2013.

[18] A. Proverawati, Aanemia and Pregnant Women. Yogyakarta, Indonesia: Nuha Medika Yogyakarta, 2011.

[19] D. Susilowati, Modul of Nursing Teaching Material: Health Promotion. Jakarta: Indonesia: Indonesian Health Ministry Jakarta, 2016.

[20] I. A. Baharini, A. N. W. Pratama, and F. M. Christianty, "Relationship of side effects of iron supplement $(\mathrm{Fe})$ with compliance of pregnant women in sumbersari health center in jember regency (the association between side effects of iron supplementation and medication adherence among pregnant women in Sumbersari Health Center Jember Regency, East Java)," Health Library, vol. 5, no. 1, pp. 35-39, 2017.

[21] E. B. Ahmed et al., "Assessment of iron and calcium supplements compliance among pregnant women attending antenatal care unit of Al-Sabah Banat primary health care unit in Ismailia, Egypt," Journal of Medical and Biological Science Research, vol. 1, pp. 24-29, 2015.

[22] H. Hasan, "Using of audiovisual media to exhaustiveness of social sciences content in technology development, production, communication, and transportation in elemantary school's 4th grade students, 20 nation elementary school banda aceh," Journal of Basic Charm, vol. 3, no. 4, pp. 22-33, 2016. 